doso en la 1

ar ejemplos a

is funcionalidac uso, dependiende encarnan los conceptos detr por e $\Lambda$ influ
$\mathrm{Pe}$ infin:

Las formas $d r$ oceso de sig ialidad .

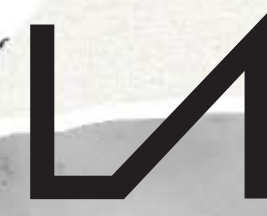

R E V I S A
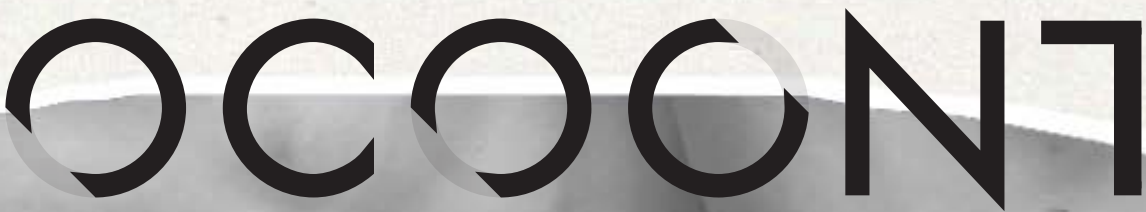

D $E$

No $6 \cdot 2019 \cdot$ ISSN 2386-8449

"El producto del diseñador es un proyecto, el estado previo de un objeto", Entrevista con Norberto Chaves, por Fernando Infante

El papel de la investigación y la teoría en diseño. Una conversación abierta, por Fernando Infante y María Jesús Godoy

UT PICTURA POESIS

Abandonar la escritura. Poesía experimental y manifiesta, Ignacio Gómez de Liaño

PANORAMA: FILOSOFÍA DEL DISEÑO Sección coordinada por Fernando Infante y María Jesús Godoy

Pensar el diseño, Fernando Infante y María Jesús Godoy (Coordinadores)

TEXTOS INVITADOS

Estatus y estado del điseño más allá del objeto, Pedro Medina Reinón

Mar de Nubes, Cuerpo de Cristal, Dionisio González

ARTÍCULOS

Understanding Design Aesthetics beyond Functional Beauty accounts, Lucía Jiménez Sánchez

Estética y diseño industrial: debates y controversias, Joan M. Marín

Del ornamento al delito. El diseño y la sociedad en Charles Baudelaire y Adolf Loos, Jorge López Lloret

When is Architecture not Design? Saul Fisher

Diseño y habitabilidad: una aproximación basada en los lenguajes de patrones, Antonio Hidalgo Pérez

Marcel Breuer: un diseñador global. Experiencias en el ámbito de la vivienda prefabricada, Salvador J. Sanchis, Ignacio Peris y Pedro Ponce Diseño y artes escénicas: el papel de Oskar Schlemmer en Das Triadische Ballett y la actualidad de la Bauhaus, Milagros García Vázquez Lo performativo en prácticas de arte y diseño actuales vinculadas a procesos de innovación social. El caso de La Venezia che non si vede y de La borda, Tània Costa Gomez

Articulaciones de la estética y el diseño. El caso de la evaluación a partir de la investigación dirigida en la carrera de diseño escénico de la Universidad de las Artes de Cuba, Mara Rodríguez Venegas y Xiomara Romero Rojas

SUPLEMENTO

El diseño, la ciudad y un lápiz de labios, Mercedes Espiau, Mar García Ranedo y Alejandro Rojas mas. 


\section{UつCつCNTE}

No $6 \cdot 2019 \cdot \operatorname{ISSN} 2386-8449 \cdot$ DOI 10.7203/LAOCOONTE.5.15381

https://ojs.uv.es/index.php/LAOCOONTE/index

COORDINACIÓN EDITORIAL

Anacleto Ferrer (Universitat de València)

Francesc Jesús Hernàndez i Dobon (Universitat de València)

Fernando Infante del Rosal (Universidad de Sevilla)

SECRETARÍA DE REDACCIÓN

Lurdes Valls Crespo (Universitat de València)

Vanessa Vidal Mayor (Universitat de València)

COMITÉ DE REDACCIÓN

Tamara Djermanović (Universitat Pompeu Fabra), Rosa Fernández Gómez (Universidad de Málaga), Anacleto Ferrer (Universitat de València), Ilia Galán (Universidad Carlos III), Ana María García Varas (Universidad de Zaragoza), María Jesús Godoy (Universidad de Sevilla), Fernando Infante del Rosal (Universidad de Sevilla), Miguel Ángel Rivero (Universidad de Sevilla), Miguel Salmerón (Universidad Autónoma de Madrid), Gerard Vilar (Universitat Autònoma de Barcelona).

COMITÉ CIENTÍFICO INTERNACIONAL

Rafael Argullol* (Universitat Pompeu Fabra), Luis Camnitzer (State University of New York), José Bragança de Miranda (Universidade Nova de Lisboa), Bruno Corà (Università di Cassino), Román de la Calle* (Universitat de València), Eberhard Geisler (Johannes Gutenberg-Universität Mainz), José Jiménez* (Universidad Autónoma de Madrid), Jacinto Lageira (Université Paris 1 Panthéon-Sorbonne), Bernard Marcadé (École Nationale Supérieure d'Arts de Paris-Cergy), Elena Oliveras (Universidad de Buenos Aires y Universidad del Salvador), Pablo Oyarzun (Universidad de Chile), Francisca Pérez Carreño* (Universidad de Murcia), Bernardo Pinto de Almeida (Faculdade de Belas Artes da Universidade do Porto), Luigi Russo (Università di Palermo), Georges Sebbag (Doctor en Filosofía e historiador del surrealismo), Zoltán Somhegyi (University of Sharjah, United Arab Emirates), Robert Wilkinson (Open University-Scotland), Martín Zubiria (Universidad Nacional de Cuyo). *Miembros de la Sociedad Española de Estética y Teoría de las Artes, SEyTA

\begin{tabular}{lll}
\hline DIRECCIÓN DE ARTE & REVISIÓN DE TEXTOS & TRANSCRIPCIÓN DE TEXTOS \\
El golpe. Cultura del entorno & Antonio Cuesta & Álvaro G. Serna
\end{tabular}

(cc) BY Excepto que se establezca de otra forma, el contenido de esta revista cuenta con una licencia Creative Commons Atribución 3.0 España, que puede consultarse en http://creativecommons.org/licenses/by/3.0/es/deed.es

EDITA

\section{SEyTA.}

CON LA COLABORACIÓN DE

\begin{tabular}{|c|c|c|c|}
\hline $\begin{array}{l}\text { VNIVERSITAT } \\
\text { B VALENCIA } \\
\text { Institut te Creativitat } \\
\text { | |nnovacions Educatives }\end{array}$ & $\begin{array}{l}\text { VNIVERSITAT } \\
\text { IE ÖVALENCIA Departament de Filosofia }\end{array}$ & 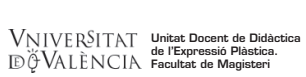 & \\
\hline $\begin{array}{l}\text { DEPARTAMENTO DE ESTÉTICA } \\
\text { E HISTORIA DE LA FLLOSOFIA }\end{array}$ & $\frac{\text { UAW }}{\frac{\text { UNIVRSSIDAD AUTONOMA }}{\text { DE MADRID }}}$ & $\begin{array}{l}\text { Universitat Autònoma } \\
\text { de Barcelona }\end{array}$ & $\begin{array}{l}\text { VNiVERSiDAD } \\
\text { Departamento de Filosofia, Lógica y Estética }\end{array}$ \\
\hline
\end{tabular}

LAOCOONTE aparece en los catálogos: 


\section{LつCつCN7E}

"Cuanto más penetramos en una obra de arte más pensamientos suscita ella en nosotros, y cuantos más pensamientos suscite tanto más debemos creer que estamos penetrando en ella".

G. E. Lessing, Laocoonte o los límites entre la pintura y la poesía, 1766.

Vo hay cól.

létodo, de pen.

:ión en general. Ith

zar la forma para el $\mathrm{n}$.

eptual por las orígenes

la, el objeto, la exposición

storia, porque existe en el $\mathrm{m}$

das sus raíces. Desde alli cc _. panoram

n conceptual y donde el émencia del con 'iseñado, como es el a al objeto y el di $\begin{array}{ll}\text { igen } \mathrm{de}^{\text {to }} \text { la inmer } & \text { tolvidada, o comc } \\ \text { trozo de madera ar }\end{array}$ a manera dorm comunicar ene nundo. Seguin? sngo en manos te el método $C$ les. A partir c teria prima $\mathrm{p}_{\mathbf{c}}$

'xto se puede:

¿ño, en proyea

amientos de $\mathrm{u}$

a conscie-

.)

en la publicación jue "plos de la impor te las nalidades porqu ura un ${ }^{2}$ diendo de qui zenerar $\mathrm{u}$ ción de nr? lne

in-

n-

is.

le http:,

le crear visualidades. A partir de.

ellas la propia materia prima para un en que desde un texto se puede generar $u_{11}$ i

Pensar en diseño, en proyección de nue

posibles comportamientos de una colecti

presente como una consciencia del hecho que estamos elaborando, significac

nuestro entorno (..)

Cardoso, R. C. Rafael. (2014). Design para um mundo complexo. Sãc asil: Cosac Naify. 


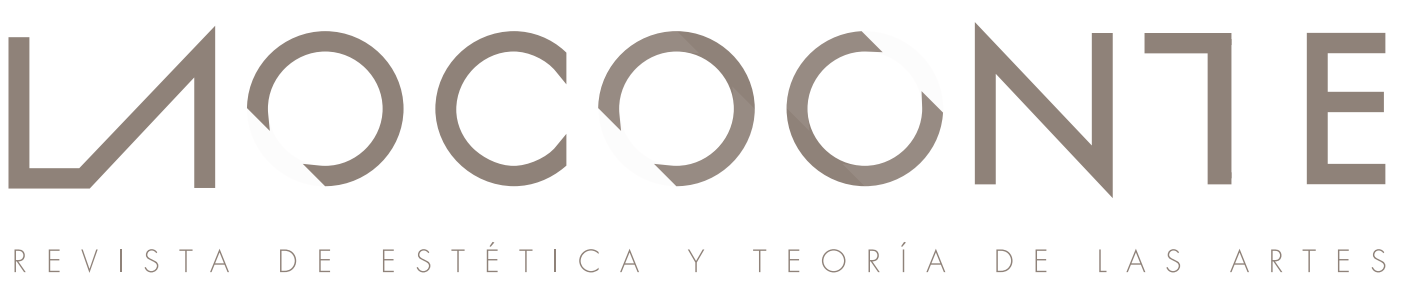

$\mathrm{N}^{\circ} 6 \cdot 2019$

PRESENTACIÓN

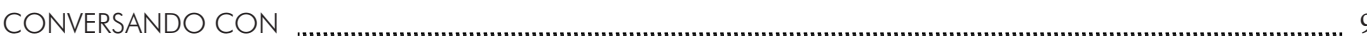

"El producto del diseñador es un proyecto, el estado previo de un objeto", Entrevista con Norberto Chaves,

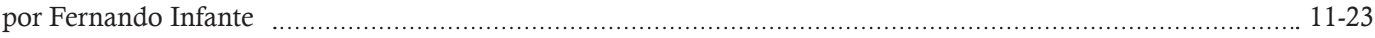

El papel de la investigación y la teoría en diseño. Una conversación abierta, por Fernando Infante

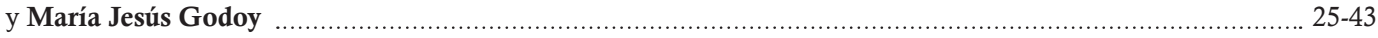

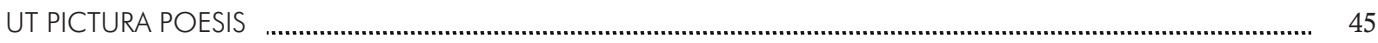

Abandonar la escritura. Poesía experimental y manifiesta, Ignacio Gómez de Liaño ................................................ 47-95

Imágenes de Laocoonte n. 6, de Isadora Gonzaga ................................................................................................... 96-97

PANORAMA

FILOSOFÍA DEL DISEÑO

Pensar el diseño, Fernando Infante y María Jesús Godoy (Coordinadores) .............................................. 101-105

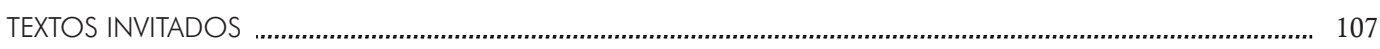

Estatus y estado del diseño más allá del objeto, Pedro Medina Reinón . ................................................... 109-125

Mar de Nubes. Cuerpo de Cristal, Dionisio González .............................................................................. 127-133

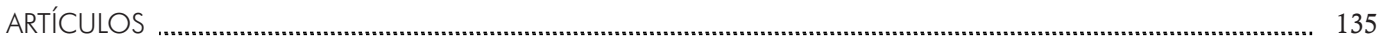

Understanding Design Aesthetics beyond Functional Beauty accounts, Lucía Jiménez Sánchez ................. 137-149

Estética y diseño industrial: debates y controversias, Joan M. Marín _...................................................... 150-164

Del ornamento al delito. El diseño y la sociedad en Charles Baudelaire y Adolf Loos, Jorge López Lloret ... $165-182$

When is Architecture not Design? Saul Fisher ……............................................................................. 183-198

Diseño y habitabilidad: una aproximación basada en los lenguajes de patrones, Antonio Hidalgo Pérez ...... 199-215

Marcel Breuer: un diseñador global. Experiencias en el ámbito de la vivienda prefabricada,

Salvador José Sanchis, Ignacio Peris y Pedro Ponce

Diseño y artes escénicas: el papel de Oskar Schlemmer en Das Triadische Ballett y la actualidad de la Bauhaus, Milagros García Vázquez

Lo performativo en prácticas de arte y diseño actuales vinculadas a procesos de innovación social.

El caso de La Venezia che non si vede y de La borda, Tània Costa Gomez

Articulaciones de la estética y el diseño. El caso de la evaluación a partir de la investigación dirigida en la carrera de diseño escénico de la Universidad de las Artes de Cuba, Mara Rodríguez Venegas

y Xiomara Romero Rojas

SUPLEMENTO 
Walter Gropius. La vida del fundador de la Bauhaus, Jorge Martínez Alcaide

¿Qué significa pensar la política desde la estética? Àger Pérez Casanovas

Ideologías estéticas en los orígenes de la pintura moderna, José Luis Plaza Chillón 300-303

Sobre a estética, Luis Carlos Pereira

Músicas populares. Sociedad y territorio: Sinergias entre investigación y docencia, Mar Aleixandre Badenes.

307-309

La necesidad de la mirada antropológica sobre la literatura, Pablo de Benito David

A propósito de Chandler, o la novela policíaca como tratado filosófico, Juan Evaristo Valls Boix

Videre aude!, Anacleto Ferrer

La inaplazable memoria del dolor y el sufrimiento, Antonio Notario Ruiz

La alargada sombra de la pintura, Raquel Baixauli

Sondear la maravilla, Juan Evaristo Valls Boix

... Y lo sabes, Marc Hernández Montoro

Arqueologías de la modernidad en las artes. Ensayo estético, Carlota Fernández-Jáuregui Rojas

Estética de la Instalación, Luis Cemillán Casis

La Herencia de otra época, María Jesús Godoy Domínguez

Del Theatrum Mundi al Gran Vidrio, Miguel Salmerón Infante

Imágenes de Isadora Gonzaga.

Fotografía de portada de Tamara Djermanovic intervenida por Isadora Gonzaga.

Los coordinadores de la sección Panorama: Filosofia del diseño agradecen

a Antonio Molina Flores su colaboración. 
ner.

llobj vidada, o de ma la publica. los de la im nalidades po ndientn $\mathrm{A}$ -
, la

que e.

usdño, si nn

ज. " da yara el mu tual y d

or enc or las orígenes un tmo, fía del diseño,

rpintero que'curra la forma de

eña Desige para un mundo complexo, de los bienes producidos por el hombre :tores subjetivos también influyen en su

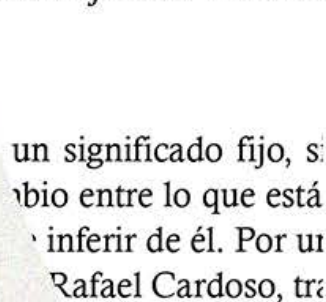

Rafael Cardoso, tri

No hay cómo no e método, de pensa 1, donde la reación en geperal. salizar la forma pa. rue amb ${ }_{\text {Snceptual por }}{ }^{1}$

$$
\text { -rola ol } n^{\prime}
$$

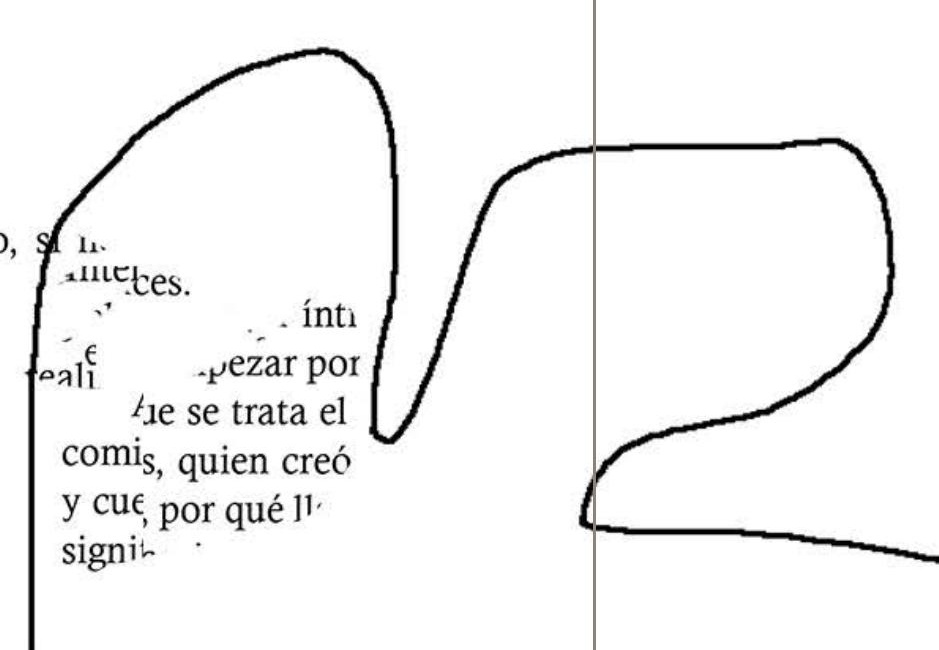

LOCOCNTE

PANORAMA: FILOSOFÍA DEL DISEÑO

Fernando Infante del Rosal y María Jesús Godoy Domínguez

(Coordinadores) 
No hay cómo no hablar de una filosofía del diseño, si no de izar la forma para el mundo sensible. Tción de formas y de la

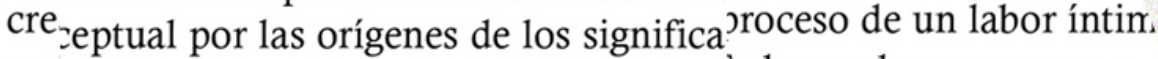

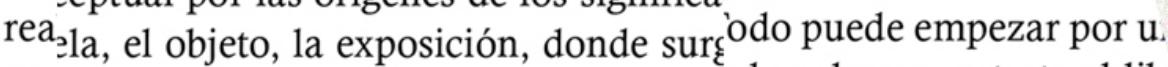

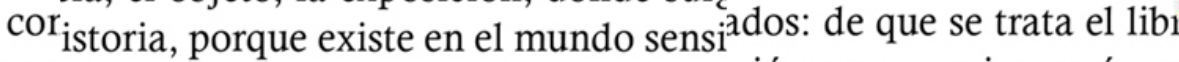
noładas sus raíces. Desde allí cojo el hilo gió, que es, quien creó y p su len conceptual y donde el está ubicado.ible o aún, por qué llama as

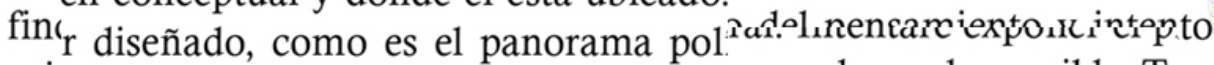
ori $_{\text {evolando la inmanencia del concepto. }}$ para el mundo sensible. Tc ce a s a forma al objeto y el diseñad ${ }^{\text {as }}$ orígenes de los significa)olo sob lengua olvidada, o como un cr la exposición, donde surg̨ido - nrocesr a un trozn de madera amnrfo le existe en el mundo sensin trai lengua olvidada,adas sus raíces. Desde allí cojo el hilona de ablo de procesc a un trozo de men conceptual y donde el está ubicado. perspectiva de lidoso en la publr diseñado, como es el panorama polndo ho, un camino diar ejemplos de levolando la inmanencia del concepto.: por una investigacióus funcionalidadı a forma al objeto y el diseñadı infl ro, el cuento, luso, dependiendı lengua olvidada, o como un $\mathrm{C} i^{\prime}$

qué, cuál e s nrecese a un trozo de madera amorfo

ata el 1

،en creó y pu.

or qué llama así, d

miento y intento a lles
- puede inferir de él. Por un in -reación ". (Rafael Cardoso, trad. 26 el ambiente que cerca el ol, especie de un danza en que ambos eleme iles son los símbolos que estso.

lmente, el contenido contextrño y hacer diseño, es antes de todo cue rna el papel de un tra o que toma la forma $\mathrm{d}^{\text {g }}$ gradual, donde la idea $\mathrm{do}_{\text {, las ideas, los relacioname }}$ danza en que ambos ropio proceso y también de r

'esign para un mundo liseñar, me planteé la cuesti' s bienes producidos por seño, es antes de tod prima eso me dá? Ejemp' es subjetivos también inf ble. Diseñar puede se ese texto, construyo el d

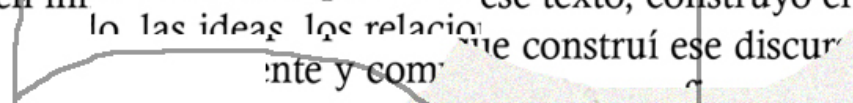

1 un significado fijo, sino que expresajue ${ }^{\dagger}$ mbio entre lo que está incrustado en Sre ¿de inferir de él. Por un lado, las form ". (Rafael Cardoso, trad. 2014)

rradual, donde la i’ 
- ormas y de rapo.

eso de un labor íntimo, un udo puede empezar por una inves 'dos: de que se trata el libro, el cu jió, que es, quien creó y por qué, ble o aún, por qué llama así, donı del pensamiento y intento a lle: Cual es el ambiente que cerca e ico. cuáles son los símholos aı

de una filosofía del diseño, si r e construcción de formas y de exponer el proceso de un labor í o sensible. Todo puede empezar los significados: de que se trata h, donde surgió, que es, quien creó y po mundo sensible o aún, por qué llama as cojo el hilo del pensamiento y intentc está ubicado. Cual es el ambiente que $\mathrm{g}$ anorama político, cuáles son los símb el concepto. Gradualmente, el conten y el diseñador encarna el papel de ur como un carpintero que toma la forr
LAU1 L11 glilla1. 111 n un sigizar la forma para e] ede inferifeptual por las orígt “. (Rafabla, el objeto, la exp istoria, porque exist y gradua adas sus raíces. De: en conceptual y do sible. $D$ : $r$ diseñado, como do, las icevolando la inman propio pri diseñar, a forma al prima e lengua olvi ese textos nrncesr a un trnzo ue construí ese discurso, he hecho de ara un reconfiguración de significado en para ilustrar... (en construccion) antiguas formas, es lanzar al mundo 1. La responsabilidad aquí se hace tamos elaborando, significados para

am mundo complexo. São Paulo,

1 agosto). Significado. Recuperado 1 br/significado/

\section{ИつCつCN7E}

PANORAMA: FILOSOFÍA DEL DISEÑO ARTÍCULOS 
- ormas y de rapon

aso de un labor íntimo, un udo puede empezar por una inves 'dos: de que se trata el libro, el cu rió, que es, quien creó y por qué, ble o aún, por qué llama así, donı del pensamiento $\mathrm{y}$ intento a lle Cual es el ambiente que cerca e ticn. cuáles son los símbolos a

de una filosofía del diseño, si r e construcción de formas y d $\epsilon$ exponer el proceso de un labor í o sensible. Todo puede empezar. los significados: de que se trata 1, donde surgió, que es, quien creó y po mundo sensible o aún, por qué llama as cojo el hilo del pensamiento y intento está ubicado. Cual es el ambiente que $q$ anorama político, cuáles son los símb lel concepto. Gradualmente, el conten y el diseñador encarna el papel de u somo un carpintero que toma la forr

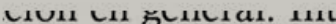
un signizar la forma para e] ambio eni ede inferieptual por las oríge n ". (Rafaəla, el objeto, la exp y gradua istoria, porque exist n danza adas sus raíces. De: en conceptual y do] sible. Dis $r$ diseñado, como do, las icevolando la inmanı ropio pri diseñar, $r$ ¥ forma al prima e lengua olvi

ese textos nrncesr a un trnzo ue construí ese discurso, he hecho de ara un reconfiguración de significado en para ilustrar... (en construccion) antiguas formas, es lanzar al mundo 1. La responsabilidad aquí se hace stamos elaborando, significados para

um mundo complexo. São Paulo,

1 agosto). Significado. Recuperado 1 $\mathrm{br} /$ significado/ 


\title{
Diseño y habitabilidad: una aproximación basada en los lenguajes de patrones
}

\section{Design and habitability: an approach based on pattern languages}

\author{
Antonio Hidalgo Pérez
}

\begin{abstract}
Resumen
En este texto se presenta un marco de trabajo inicial de lo que entendemos como una teoría del diseño basada en los lenguajes de patrones. Esta teoría del diseño se incluye dentro de una reflexión más amplia sobre las condiciones de habitabilidad de nuestra especie. Reflexión que denominamos "filosofía del habitar o de la habitabilidad". Con ese objetivo, recuperamos algunas de las investigaciones del arquitecto y urbanista Christopher Alexander. Argumentamos a favor de una pequeña corrección del modelo que él propone para analizar los patrones. Complementamos esta reflexión reclamando pensar el diseño dentro de una teoría de las necesidades (Max-Neef) y un enfoque basado en procesos (Reschel). Todo ello acuerdo con una perspectiva que asume rigurosamente los límites biofísicos del planeta. Se trata, por tanto, de avanzar en un programa de investigación sobre el diseño de habitabilidades ecológicamente viables.
\end{abstract}

Palabras clave: patrones, diseño, habitabilidad, necesidades, procesos.

\begin{abstract}
In this text, an initial framework of what we understand as a theory of design based on pattern languages is presented. This theory of design is included within a broader reflection on the habitability conditions of our species. A reflection that we call "Philosophy of the Inhabiting or of the livability". With that goal, we recover some of the researches of the architect and town planner Christopher Alexander. In addition, we argue in favor of a small correction of the model he proposes to analyze the patterns. We complement this reflection by claiming to think the design within a theory of needs (Max-Neef) and a process-based approach (Reschel). All this in accordance with a perspective that rigorously assumes the biophysical limits of the planet. That is, therefore, a question of advancing in a research programme on the design of ecologically viable habitats.
\end{abstract}

Keywords: patterns, design, needs, livability, processes.

\section{Introducción}

Desde la década de los sesenta, pero especialmente en los años setenta, el arquitecto y urbanista Christopher Alexander elabora una interesante reflexión sobre lo que denomina "lenguajes de patrones". Nos referimos a obras como El orden intemporal de construir (1971), El experimento de Oregon (1975) y Un lenguaje de patrones (1979). En línea con otros autores que ya han advertido sobre su interés filosófico (Broncano 2000),

* IES Juan Carlos I, Murcia, España. antonhida.p@gmail.com

Artículo recibido: 22 de julio de 2019; aceptado: 18 de octubre de 2019 
consideramos que muchas de las ideas que Alexander presenta en sus obras deben ser recuperadas y ampliadas en el sentido particular de una filosofia de la habitabilidad, en cuyo centro se encuentra el problema del diseño de patrones y, por extensión, el de la gobernanza de las ciudades. Se trataría de iniciar un programa de investigación sobre nuestros estilos habitacionales, en un momento en el que se multiplican los riesgos derivados de la crisis ecológica global, la desigualdad planetaria creciente y los desarrollos de la tecnociencia (Riechmann 2014).

Dado ese objetivo, en este artículo comenzamos presentando un modelo de interpretación de esos patrones, que nos han de servir como instrumentos de racionalidad. Proponemos, a continuación, examinar la práctica del diseño a la luz de una concepción de las necesidades humanas según el modelo de Max-Neef $(1986,1998)$, ofreciendo así un posible desarrollo de la relación entre ética y diseño. Por supuesto, la satisfacción de necesidades no es el único factor determinante del diseño de patrones: también lo son los límites biofísicos del planeta, tema que aquí, sin embargo, quedará tan sólo apuntado. No obstante, planteamos al final un marco general de la filosofía de la habitabilidad basado en cuatro dominios habitacionales básicos, que ha de permitir integrar y ordenar las cuestiones tratadas hasta el momento. Apoyándonos en el enfoque procesual de Reschel (2000), esta parte facilitará, a su vez, corregir parte de la teoría de las necesidades introduciendo lo que denominamos "procesos de orden pragmático"; es decir, los patrones de acción a los que el diseño tiene la tarea de dar una determinada infraestructura.

Consideramos que este marco de trabajo, del que aquí presentamos sólo una pequeña parte, permite a la filosofía evitar las frecuentes discusiones "semánticas" sobre la ciudad y comenzar a elaborar un orden común de discusión para dar cuenta del problema de la habitabilidad desde un punto de vista no sólo crítico, sino también constructivo.

\section{Patrones como unidades mínimas de organización de lo habitacional}

¿Por qué es importante definir un modelo al hablar de patrones? Lo primero, porque un modelo sirve como filtro para obtener información relevante y suficiente, o que se juzga como tal, sobre aquello que se desea investigar. Los criterios utilizados en su elaboración nos han de proporcionar una perspectiva, y si esta perspectiva no responde adecuadamente a la complejidad del objeto de investigación, la información que manejemos puede resultar escasa e inducir planteamientos incorrectos. Nuestro objetivo es poner en el centro de la reflexión filosófica el problema de la habitabilidad. Por tanto, si tenemos razón al afirmar que los patrones son las unidades mínimas de organización de lo habitacional, esto es, que no existe forma de habitabilidad que no se presente organizada según un determinado conjunto o lenguaje de patrones, lo primero que debemos hacer es explicar en qué consisten éstos en términos estructurales. El modelo propuesto nos permitirá entonces disponer de un primer marco para pensar lo habitacional y establecer las bases críticas del diseño. Lo que sería un diseño de habitabilidades ecológicamente viables.

Pero antes de presentar nuestra propuesta (apdo. 2.1), en la que argumentamos a favor de corregir el modelo a tres niveles de Alexander por otro de cuatro niveles o dimensiones estructurales, quisiéramos recordar algunas de las razones que justifican ordenar la reflexión sobre la arquitectura y el urbanismo desde un enfoque basado en los lenguajes de patrones. Posteriormente (apdo. 2.2), utilizaremos el modelo 
propuesto para deducir cuatro categorías básicas de la pragmática del diseño. El hilo de la argumentación nos ha de conducir, desde aquí, a la identificación de algunos principios de orden constructivo, como el principio de limitación, cuya introducción servirá de puente entre el análisis estructural de los patrones y la reflexión sobre patrones y necesidades que ocupa la segunda parte de este artículo.

Al introducir la cuestión de los patrones, Alexander no se fija en ningún estilo arquitectónico particular, sino más bien en la forma de adaptarse al medio natural que demuestran todas las sociedades humanas. Esta adaptación se concreta, siempre, mediante la configuración de un entorno que se entiende como "artificial". Un pozo, una casa, un camino. Estilos de adaptación, a los que Alexander se refiere, en términos generales, como "modos de construir" que varían de una cultura a otra, pero tienen en común, sin embargo, que se despliegan y objetivan a través de múltiples "estructuras físicas", de elementos que se entrelazan unos con otros en tanto que "componentes fundamentales de la construcción" (1981: 24). Pues bien, tales estructuras o componentes, en tanto que unidades mínimas de cualquier organización de la vida individual y colectiva, son lo que Alexander denomina patrones. En este sentido, los patrones son las condiciones de posibilidad de cualquier régimen de habitabilidad. De ahí la centralidad del diseño: es parte integral del proceso mismo de habitar. Así pues, más allá de las particularidades de cada uno, el enfoque basado en los lenguajes de patrones proporciona ese orden común de discusión al que nos referíamos antes porque nos permite elaborar un marco teórico fundando sobre aquello que comparten todos los modos de construir que conocemos.

Aunque sin profundizar en ello ni explorarlo con el rigor necesario, ${ }^{1}$ Alexander reconoce que los patrones que dan sentido y "carácter" a un lugar, no son necesariamente patrones de carácter físico o patrones relativos a la acción humana. Los patrones que Alexander denomina "de acontecimientos" hacen referencia al conjunto de eventos o sucesos de orden natural, mecánico o social, de los que depende el frágil equilibrio o identidad de este o este lugar:

El paso de los trenes, la caída del agua, el lento agrietarse de las estructuras, el crecimiento de la hierba, el derretimiento de la nieve, la oxidación del hierro, el florecimiento de las rosas, el calor de un día de verano, cocinar, hacer el amor, jugar; y no sólo los acontecimientos de nosotros mismos sino de los animales, de las plantas, incluso de los procesos inorgánicos (1981: 66).

En cierto modo, estos patrones de acción se podrían interpretar en términos de "habituaciones", según los planteamientos sociológicos de Luckmann y Berger (2001). Tampoco resultaría difícil ampliar esta noción con las importantes aportaciones de Marcel Mauss (1979), Pierre Bourdieu o, más recientemente, Ingold (2008: 1-35). Las "técnicas corporales" del primero o la noción de "habitus" del segundo explican bastante bien esa idea de los patrones como formas, antropológica e históricamente determinadas, por medio de las cuales ordenamos generativamente nuestras acciones. Como diría Bourdieu, los patrones de acción conforman "sistemas de disposiciones duraderas y transferibles",

1 Al final presentamos una versión ampliada de estas ideas de Alexander. Apoyándonos en Reschel (2000), distinguimos cuatro tipos de estructuras procesuales (de orden natural, técnico, pragmático y sistémico), y damos contenido a los terceros (es decir, a los patrones de acción) identificando cuatro modalidades: patrones de concentración, de conservación, de dispersión y de generación. 
en las que se juega tanto lo que nuestra experiencia tiene de "estructurado", puesto que son producto de las historias y los contextos a los que pertenecemos, como de capacidad "estructurante", dado que también tenemos la capacidad de autocorregirnos, modificar nuestros patrones o modos de relación, y coordinarnos bajo apreciaciones y objetivos distintos (2007: 86). En palabras de Alexander: "Ellos [los patrones] son las reglas a través de las cuales nuestra cultura se conserva y se mantiene viva, y somos seres de nuestra cultura estructurando nuestras vidas a partir de estos patrones de acontecimientos" (1981: 68). Todo ello concuerda, además, con la idea desarrollada por Lahire acerca de nuestra condición de "actores plurales", formados en "una pluralidad de mundos sociales no homogéneos" a los que debemos la pluralidad de repertorios de acción que ponemos en funcionamiento día a día:

Los repertorios de esquemas de acción (de hábitos) son conjuntos de compendios de experiencias sociales que han sido construidos-incorporados en el curso de la socialización anterior en marcos sociales limitados-delimitados; y lo que cada actor adquiere progresivamente, y de un modo más o menos completo, son tanto unos hábitos como el sentido de la pertenencia contextual (relativa) de su puesta en práctica (2004: 55).

Al hablar de patrones nos encontramos ante un repertorio pragmático de nuestra especie, esos elementos o "resortes" que encontraríamos en cualquier inventario sobre las "formas de ser que existen en el mundo", dirá Alexander. Una suerte de condensadores de las memorias, experiencias, procesos de socialización, proyectos comunes, etc., explica Lahire, que nos distinguen como individuos, miembros de una cultura y una especie, y por medio de los cuales desplegamos las secuencias o cursosde-acción propios de nuestros estilos o culturas habitacionales. "Cada persona dentro de una cultura vive su vida pasando de una situación a otra, la construye como una suerte de collar en la que se van enhebrando todas aquellas situaciones que están a su alcance" (1971: 113).

Ahora bien, como es evidente, tales patrones o formas de vida dependen necesariamente de multitud de infraestructuras, los "esquemas de espacio" a los que también se refería Lefébvre: "Esquema generador ligado a una praxis, a una realidad y a una verdad dentro de los límites de una sociedad" (1976: 38); o Goffman al hablar de los "anclajes de nuestros haceres" como parte de la dimensión logística, fundamental para entender su idea de "marcos sociales" (2006: 260). En este sentido, diríamos que las sociedades humanas, vistas desde la perspectiva de sus repertorios y secuencias de acción, recrean a través de sus lenguajes de patrones los "cuadros espaciales que sus conductas requieren", como observa Alexander. Se podría hablar, siguiendo a Lukács, de "legalidades objetivas del ser social" o "formas de objetividad del ser social que crecen en el cauce de la emergencia y del despliegue de la praxis social" (2007: 77). Todo lo cual permite pensar los lenguajes de patrones espaciales como conjuntos de "categorías culturalmente definidas en el espacio", donde "cada una de ellas define una actitud o un lugar o una cosa y sus respectivos comportamientos humanos" (1971: 96). "Por esta razón -concluye Alexander-, expreso que el planeamiento de una ciudad es el diseño de la cultura" (1971: 113). En este sentido, escribe Broncano:

La idea de cultura como conjunto de redes de posibilidades prácticas nos permitirá aproximarnos a la idea de artefacto desde la perspectiva de las posibilidades prácticas 
determinadas por (y determinantes de) las capacidades humanas. Los artefactos constituyen los portadores de los espacios de posibilidad que los humanos crean. No son meras affordances físicas, ni siquiera affordances meramente funcionales, son redes de sentido que actualizan las trayectorias que constituyen la vida humana (2009: 55).

Por tanto, si queremos disponer de una teoría del diseño de tales infraestructuras habitacionales, capaz de servir como programa a la vez crítico y constructivo, un ejercicio fundamental será determinar lo que se entiende por patrones, explicar en qué consisten las unidades mínimas de las que se componen dichas infraestructuras.

2.1. Un modelo de cuatro dimensiones: constitutiva, compositiva, morfológica y valorativa.

¿Cuál es la posición de Alexander? ¿Qué definición ofrece de los patrones? En términos generales, dice Alexander que:

Podemos definir un patrón como un principio general del diseño y del planeamiento a través del cual se formula un problema concreto que puede presentarse repetidas veces en cualquier proceso de diseño. Además, delimita el tipo de contextos en los cuales este problema puede ocurrir y muestra las características esenciales que ha de poseer cualquier edificio. En este sentido, podemos afirmar que un patrón es un imperativo empírico que formula las condiciones mínimas necesarias para conseguir la salud individual y colectiva de una comunidad (1976: 66).

Teniendo esto en cuenta, es posible formular una definición más breve y formalmente interesante afirmando, como hace Alexander, que un patrón es "una regla tripartita, que expresa la relación entre un contexto determinado, un problema y una solución" (1981: 199). Esta fórmula sintetiza perfectamente el modelo a tres niveles que él plantea: un contexto de referencia, siempre; una reconstrucción reflexiva de las "fuerzas" o "tendencias" en conflicto o dispuestas de manera injusta, perjudicial o ineficiente; $y$, en tercer lugar, una configuración orientada a ordenar las cosas de modo tal que el conflicto se reduzca o desaparezca, es decir, dirigida a ganar estabilidad, completitud. Se trata, por tanto, de instituir un orden o conjunto organizado de relaciones distinto, nuevas "leyes morfológicas", según escribe:

Cada uno de estos patrones es una ley morfológica que establece un conjunto de relaciones en el espacio [...] Y cada ley o patrón es, en sí mismo, un patrón de relaciones entre otras leyes, que en sí mismas sólo son, asimismo, patrones de relaciones (1981: 84-85).

Aunque no es el momento de exponer las conclusiones que se deducen de aquí, resulta evidente que, conforme a este modelo, el diseño basado en los lenguajes de patrones no puede ser sino un diseño de carácter situado. Lo cual es decisivo, por ejemplo, a la hora de pensar procesos de traslación y adaptación técnica, tal y como ha avanzado Vega Encabo (2004: 51-71). Pero no sólo situado, sino también, y precisamente por ello, pluralista y abierto a procesos de corrección reflexiva con el objetivo -al menos el objetivo que nosotros defendemos- de reforzar la viabilidad de nuestros sistemas habitacionales. No obstante, lo que nos interesa ahora es más bien exponer en qué sentido consideramos que este modelo de Alexander debe ser mejorado y ampliado. Según nuestra propuesta, esas tres partes que acabamos de identificar -contexto, problema y solución- se corresponden, respectivamente, con tres de las 
cuatro dimensiones estructurales de los patrones que expondremos aquí: la dimensión constitutiva, la dimensión compositiva y la dimensión morfológica. Un breve comentario acerca de cada una estas dimensiones.

1) Hablamos de dimensión constitutiva con el objetivo de subrayar la naturaleza constitutiva, y por tanto el carácter de exigencia o compromiso para el diseño de patrones, que poseen todos y cada uno de los elementos que encontramos en un contexto determinado, desde las condiciones medioambientales o la materialidad misma de los patrones hasta los conjuntos de acciones involucradas o los programas y valoraciones que rigen, de fondo, en ese contexto. El contexto no es un mero recorte en el paisaje. De hecho, Alexander se refiere a tales elementos constitutivos en términos de "orígenes funcionales de la forma" (1969: 21), si bien falta en su obra un desarrollo más profundo y sistemático de los mismos (es lo que pretendemos empezar con los denominados dominios o ámbitos habitacionales, al final de este artículo).

2) La dimensión compositiva, en cambio, sirve para dar cuenta de la reconstrucción crítica que Alexander identifica como el auténtico "cuerpo" de los patrones. Es conveniente plantear el caso en términos de composición porque, según lo apuntado antes, los problemas son el resultado de nuestra reflexión sobre los desajustes que observamos en los patrones habitacionales existentes (desajustes que se traducen, por ejemplo, en el incremento de los riesgos, y por tanto de la vulnerabilidad, de una población). Los problemas, diremos, no vienen dados, sino que debemos componerlos, y hacerlo de manera tal que, señala Alexander, logremos obtener una perspectiva exacta sobre aquello a lo que aspiramos a dar una respuesta interesante y valiosa; es decir, lo contrario a dar cuenta de ciertas fuerzas "a expensas de otras que quedan sin resolver" (1981: 221). Por supuesto, componer dicha perspectiva puede ser, según el caso (por ejemplo, dependiendo de la escala), un ejercicio difícil y complejo, pero esto no impide comprender la dimensión compositiva como aquella en la que "se describe el trasfondo empírico del patrón, las evidencias a favor de su validez” (1971: 89).

No obstante, y ciertamente en unos casos más que en otros, no se trata de una composición exclusivamente técnica, sino también social, en la medida en que estas composiciones de las que hablamos son la expresión de una toma de posición eminentemente ética y política. En la dimensión compositiva, por decirlo así, se "cocinan" nuestros proyectos éticos. Es en el momento de la composición cuando se ponen de manifiesto cuáles son, y de qué tipo, nuestros compromisos y objetivos como sociedad; cuál es nuestro sentido de lo valioso y lo deseable. Según lo diría Ortega, en la composición se juega una auténtica crítica del deseo (Ortega y Gasset 2015); el momento de seleccionar conjuntamente entre las "posibilidades pragmáticas" (Broncano 2000) del contexto. Esto es fundamental en Alexander, que apuesta muy decididamente por introducir mecanismos de mayor calidad democrática en el diseño y la planificación de las ciudades. Para Alexander, este ejercicio de composición debía ejecutarse ampliando y mejorando al máximo la colaboración con la ciudadanía: no sólo implicándola, sino reconociéndola como un agente más, y decisivo, en el proceso de diseño. Lo cual implica, entre otras cosas, realizar previamente un examen riguroso de las condiciones bajo las cuales la participación ciudadana puede ser razonablemente virtuosa, un requisito que encontraremos posteriormente al desarrollar el tema 
de las necesidades, ${ }^{2}$ y que Alexander pretende recoger al formular su "principio de participación":

Todas las decisiones acerca de qué se ha de construir y de cómo se ha de construir han de estar en manos de los usuarios. [...] El equipo de especialistas de la planificación debe entregar a los miembros de los equipos de diseño los patrones, los métodos de diagnóstico y toda la ayuda adicional necesaria que precisen para diseñar (1976: 42).

3) En cuando a las "soluciones", optamos por subrayar su carácter morfológico porque los patrones, en su momento de instalación, no son sino conjuntos organizados de relaciones, "leyes morfológicas" o "patrones de relación", según la expresión citada de Alexander. En la dimensión morfológica se especifican las instrucciones que explican cómo es el patrón propiamente dicho, cuál es su orden particular. Lo morfológico, en este sentido, nos sitúa frente al problema central del diseño: lograr que en un contexto $(\mathrm{X})$, mediante tal o cual arreglo causal ( $r$ ), se proporcione acomodo o se facilite la realización de una pauta de acción (y), cumpliendo esto (A) y esto (B) y esto (C), y así sucesivamente hasta completar la lista de factores cuya consideración permite que $(r)$ sea óptimo en ese contexto (X). Pero debemos evitar suponer que tales ordenamientos genéricos proporcionan soluciones definitivas. Aunque en la reflexión de Alexander encontramos una defensa valiente de la alta necesidad de ciertos patrones, él mismo reconoce que los patrones son "reglas empíricas", "hipótesis" continuamente a prueba.

Por otro lado, es importante tener en cuenta que los patrones, según la propuesta de Alexander, no son recetas para aplicar mecánicamente; al contrario, se trata de instrucciones con-o que deben poseer-un alto grado de realizabilidad en circunstancias diferentes, lo que Lawler y Vega Encabo denominan "realizabilidad múltiple" (2011: 167-178). Alexander se refiere concretamente a la "variación y singularidad que siempre hay en la forma en que se manifiestan los patrones" (1981: 125).

Cada solución -observa- se formula de manera que nos dé el campo esencial de relaciones necesarias para resolver el problema, pero de un modo muy abstracto y general, con lo que usted puede resolver el problema por sí mismo, a su modo, adaptándolo a sus preferencias y a las condiciones locales del lugar en que está haciéndolo (1980: 11).

4) Ahora bien, ¿bastan estos tres niveles - constitutivo, compositivo y morfológicopara dar cuenta completamente de la complejidad intrínseca de los patrones y, por tanto, de la práctica del diseño de habitabilidades? Nuestra respuesta es que no. Desde el principio hemos sostenido que los patrones expresan y objetivan tomas de posición de carácter ético, es decir, de acuerdo a valores, entendidos como "generalizaciones inmanentes en lo racional" (Luhmann, 1998) o "funciones", según reclama Javier Echevarría en su "axiología de la tecnociencia" (2003; 2017). Si esto es así, debemos aceptar la premisa de que los arreglos morfológicos no son nunca neutros, ni pueden serlo, sino que se diseñan y ejecutan conforme a una finalidad o finalidades determinadas, un propósito

2 Más que examinar las distintas metodologías que se manejan, interesa subrayar que la colaboración es una práctica fundamental del proceso de diseño según el enfoque que presentamos. Los márgenes de maniobra pueden luego variar (dependiendo de la escala, tipo de problemas, etc.), pero pensamos que ante problemas de difícil solución o cuya solución no conocemos (wicked problems), es más razonable la opción de una participación bien reglada y efectiva que su reducción o negación. 
o unos principios. Por eso nos parece razonable corregir el modelo a tres de Alexander incorporando un cuarto nivel, que llamaremos valorativo. Es un cambio importante, puesto que nos permite introducir con una mayor sistematicidad -y poner en primera línea del debate- la relación entre diseño y ética, o si se prefiere, la cuestión relativa a la axiología del diseño.

En definitiva, según el modelo presentado, sostenemos que los patrones deben ser analizados en términos constitutivos, compositivos, morfológicos y valorativos, de lo cual deducimos una posible definición: los patrones, diremos, son arreglos materiales causal y axiológicamente orientados.

\subsection{Hacia una pragmática del diseño y la habitabilidad}

A partir de estas cuatro dimensiones, con las que pretendemos formular un posible modelo de análisis de los patrones de habitabilidad, se abre un programa de investigación muy amplio sobre el diseño y la gobernanza de nuestras ciudades. Lo que presentamos ahora es una parte mínima, pero importante en cuanto a la pragmática del diseño que se sigue de lo expuesto. De acuerdo, por tanto, con la diferencia entre lo constitutivo, lo compositivo, lo morfológico y lo valorativo, entendemos que la pragmática del diseño está determinada por cuatro factores; factores que identificamos a partir de la lógica propia de cada una de esas dimensiones o áreas operatorias que hemos identificado. Pues bien, en relación con la dimensión constitutiva, sostenemos que el diseño de patrones precisa de una inteligencia para las predeterminaciones; en cuanto a la dimensión compositiva, diremos que su lógica propia tiene que ver con lo proyectivo; por su parte, la dimensión morfológica pone en primera línea la cuestión de los ajustes; mientras que lo que rige en lo valorativo es la cuestión de los fines. De ello es posible derivar cuatro principios constructivos: limitación, colaboración, adaptación y pluralidad, si bien aquí nos ocuparemos solamente del primero.

1. ¿Por qué hablamos de predeterminaciones? Si aceptamos que el contexto es algo que viene dado, es decir, que existen multitud de elementos constitutivos (clima, un entorno construido, personas con tales o tales hábitos, valores, etc.), entonces no podemos negar el hecho de que el diseño de patrones opera siempre dentro de un espacio lleno de constricciones o predeterminaciones que describen su paisaje de posibilidades. Por supuesto, esta idea de predeterminación no implica que se anule necesariamente nuestra capacidad de intervención. Lo que ocurre más bien es que se acota un cierto margen de maniobra cuya realidad habrá que descubrir una vez conozcamos la complejidad del contexto de referencia. Es de suponer que habrá determinaciones sobre las que se podrá intervenir para revertir su condición de tales, así como determinaciones sobre las que será imposible o muy difícil cualquier tipo de intervención.

2. Además de estas predeterminaciones, la pertinencia de los patrones se juega en la exactitud con que se realice el ejercicio de proyección relativo a cada uno; es decir, la composición del proyecto. Lo que componemos a partir de las limitaciones o posibilidades que impone el contexto. Se trata de ejercicio de registro e ideación por medio del cual se consigue representar crítica y colaborativamente el problema al que nos enfrentamos. Es sugerente hablar de una lógica proyectiva en relación a la dimensión compositiva porque el significado literal de "proyección" es "lanzamiento 
hacia adelante", y parece que eso es precisamente lo que explica la razón de ser de lo compositivo. En el proyecto no se copia o describe meramente lo que sucede, sino que se introduce todo aquello que estamos en condiciones de pensar, analizar, formular, expresar... incluidos los objetivos que somos capaces de fijar colectivamente en base a nuestros sistemas de valoración, lo que deseemos conservar o defender por el valor que le asignemos como sociedad; y todo ello, en definitiva, para ir más allá de los problemas que revelan nuestros sistemas habitacionales. En cierto modo, el proyecto nos conduce a hablar también de teoría, en la medida en que el proyecto es la arquitectura teórica del ejercicio del diseño.

3. En cuanto a la lógica propia o razón de ser de la dimensión morfológica, hemos propuesto hablar de operaciones adaptativas de ajuste. Entendemos que los patrones, en su formulación concreta, tienen como función primera la de ordenar lo habitacional de un modo y otro, y esto quiere decir ajustar los elementos en juego -recursos, bienes, necesidades, hábitos, etc.- bajo una regla y estructura específica. Es un problema de forma: intervenir sobre las fuerzas o tendencias en conflicto para corregirlas y orientarlas por medio de arreglos causales distintos, es decir, instituyendo un modo concreto de ajustar las cosas. Dos ejemplos ${ }^{3}$ de patrones que formula el propio Alexander para ver esto con más claridad:

[Gradiente de intimidad] Trace los espacios de un edificio de un modo que creen una secuencia que comience con la entrada y las partes más públicas, pase por áreas ligeramente más privadas y termine en los dormitorios de privacidad máxima (1980: 546).

[Los objetos de su vida] No se deje engañar por la idea de que la decoración moderna ha de ser repulida o sicodélica, 'natural' o 'arte moderno', 'plantas' o cualquier otra cosa que reclamen los hacedores de gustos del momento. Es más bello cuando nace directamente de su vida, de las cosas que a usted le importan, de las cosas que le dicen algo (1980: 253).

4. No obstante, falta por identificar la lógica propia de dimensión valorativa. En este caso, diremos que se trata de un asunto de finalidad, dado que las posiciones axiológicas o de carácter ético se traducen en el ámbito del diseño habitacional en términos teleológicos. El diseño de patrones es una práctica con arreglo a fines, y son esos fines -esa pluralidad de fines- los que conforman el núcleo axiológico de los mismos. De ahí que la relevancia otorgada a ciertos valores, en determinadas circunstancias, tenga como primera consecuencia la necesidad de corregir nuestros lenguajes de patrones bajo fines acordes a ellos. No hay relaciones de ajuste que no estén axiológicamente orientadas, es decir, ejecutadas bajo un orden de finalidades, de unos principios, porque no hay proyecto que se componga sin una problematización de los valores y deseos que forman parte de nuestras vidas y estilos habitacionales.

En definitiva, sostenemos un modelo de patrones donde se distinguen cuatro dimensiones, las que denominamos constitutiva, compositiva, morfológica y valorativa.

3 Queremos subrayar que los traemos como ejemplos de lo que venimos exponiendo, no para defender que proponen una solución correcta. Lo que nos interesa no es la solución que expresan estos patrones, sino que todos los patrones deben expresar una. 
A partir de aquí deducimos que el diseño de patrones, lo que vendría a ser la pragmática del diseño, se juega entre cuatro factores de lo que se debe dar cuenta: las predeterminaciones que definen el paisaje de posibilidades del diseño; la composición de un proyecto, en el que se obtiene una representación crítica y reflexiva sobre el problema que se debe resolver; una operación de ajuste, cuyo objetivo es reordenar de nuevo la situación; y la institución, por ende, de una constelación o mixtura de finalidades en las que se expresan los objetivos de la sociedad y sus aspiraciones habitacionales.

De las conclusiones que se pueden extraer de aquí señalaremos al menos una, que tiene que ver con las predeterminaciones. Éstas sugieren registrar la idea de límite como una de las ideas fundamentales de la teoría de lo habitacional, puesto que tales son, todas y cada una, e independientemente de su naturaleza particular, limitaciones operatorias que condicionan radicalmente la práctica del diseño y la planificación. En este sentido, como hemos apuntado, uno de los principios rectores del diseño debe ser lo que denominamos principio de limitación, que establece, según lo dicho, que el diseño de patrones debe ejercerse como una inteligencia de los límites que condicionan de manera más o menos irreversible nuestros sistemas habitacionales. Ahora bien, cabe preguntarse de qué límites hablamos. A continuación presentamos un posible desarrollo, de acuerdo con la teoría de las necesidades, que permitía pensar los "límites antropológicos" del diseño habitacional.

\section{Teoría de las necesidades e integridad habitacional}

De las cuestiones importantes que surgen cuando nos interrogamos sobre el acto de habitar, la de las necesidades es una de ellas. Resulta difícil pensar que una reflexión sobre la habitabilidad pueda tener éxito si no incluye una buena teoría de las necesidades. A nuestro parecer, es el marco desde el que se puede elaborar una racionalidad habitacional bien armada normativamente, sobre todo teniendo en cuenta el contexto actual de emergencia energética y la complejidad de revertir las fracturas metabólicas sobre las que se erigen nuestros sistemas habitacionales (Sempere 2018).

Se trata de conducir la reflexión, según la invitación de Sloterdijk, hacia una "teoría positiva de la posición íntegra" o "de la vida bien posicionada" (2006: 408); es decir, de plantear el problema de lo habitacional desde la necesidad -universal, de la especie- de conservar un cierto equilibrio relativo a nuestro bienestar, un equilibrio que bien podríamos recoger mediante la noción de integridad. Adolf Loos lo resume de manera muy atractiva: "La manta es el detalle arquitectónico más antiguo" (2003: 149). La arquitectura - o el diseño de patrones- no aparece desde esa perspectiva sino como técnica de mediación entre los recursos de que disponemos y la satisfacción, por ejemplo en este caso, de la necesidad de protegernos de las inclemencias del tiempo, de conservar un poco de calor para dormir bien. Los lenguajes de patrones deberían permitirnos pensar lo habitacional en el mismo sentido: como dispositivos o instrumentos de organización de nuestra integridad habitacional. Formas del diseño para una vida buena. Para ello nos serviremos de ciertas ideas expuestas por MaxNeef, que presentamos brevemente a continuación.

\subsection{Necesidades, satisfactores y bienes}

Según Max-Neef, las necesidades "son finitas, pocas y clasificables", y aun a riesgo de exigir ciertas modificaciones en función del momento histórico o la cultura, cabe afirmar que tienden a repetirse lo suficiente como para sostener que forman un 
repertorio relativamente cerrado. Tomémoslas, por tanto, como hipótesis de trabajo, sin entrar a discutir si sobra o falta alguna. Por otro lado, sostiene el chileno que existen dos categorías fundamentales de necesidades que se entrecruzan continuamente: las "existenciales" y las "axiológicas". Dentro de la primera se incluirían las necesidades de ser, tener, hacer y estar, dentro de la segunda, en cambio, encontraríamos las necesidades de subsistencia, protección, afecto, entendimiento, participación, ocio, creación, identidad y libertad. En cuanto a las primeras, un apunte: si la necesidad de ser "registra atributos, personales o colectivos", la de tener "registra instituciones, normas, mecanismos, herramientas (no en sentido material), leyes, etc.", mientras que las necesidades de hacer y estar registran, respectivamente, "acciones, personas o colectivas" y "espacios y ambientes" (1998: 58-59).

No obstante, y esta es una distinción fundamental de la teoría de Max-Neef, es un error no diferenciar "entre lo que son propiamente necesidades y lo que son satisfactores de esas necesidades" (1998: 41). De hecho, escribe el chileno que "lo que cambia, a través del tiempo y de las culturas, es la manera o los medios utilizados para la satisfacción de las necesidades" (1998: 42). No cambian las necesidades, sino los satisfactores, donde convergen "formas de organización, estructuras políticas, prácticas sociales, condiciones subjetivas, valores y normas, espacios, contextos, comportamientos y actitudes; todas en una tensión permanente entre consolidación y cambio" (1998: 50). De lo cual se deduce que los satisfactores son instrumentaciones en las que se expresan, a través de su propia articulación, segmentaciones sociales, asimetrías de poder, división del trabajo, acumulaciones de capital, jerarquías sistémicas... En suma, las estrategias de racionalidad que rigen lo habitacional, sea conservando un sentido fuerte de la integridad, o sea, por el contrario, instituyendo y generalizando formas de vida precarias, insostenibles, y mucho más vulnerables a los riesgos. Así, escribe Max-Neef:

Cada sistema económico, social y político adopta diferentes estilos para la satisfacción de las mismas necesidades humanas fundamentales. En cada sistema, éstas se satisfacen (o no se satisfacen) a través de la generación (o no generación) de diferentes tipos de satisfactores. [...] Lo que cambia es la elección de cantidad y calidad de los satisfactores, y/o las posibilidades de tener acceso a los satisfactores requeridos (1998: 42).

Nada de esto cuadra con la creencia de que las necesidades, como dijera Baudrillard, son "puras funciones generadas por efecto de la ideología dominante" (1974: 52-87). Que un determinado sistema de producción requiera instituir un cierto estilo $u$ orden en la satisfacción de las necesidades no implica que las necesidades sean un invento ideológico. La distinción entre necesidades y satisfactores permite salir de esta pequeña trampa y, al mismo tiempo, utilizar las necesidades como fuerza de resistencia e instancia crítica frente a las perjudiciales o indeseables modalidades de satisfacción. Unos satisfactores, por cierto, que desde nuestro punto de vista poseen una función y naturaleza equivalente a los patrones de habitabilidad, siendo así que, a partir de estas reflexiones de Max-Neef, parece razonable que en el debate sobre la relación entre necesidades y diseño, los patrones o infraestructuras habitacionales sean pensados precisamente como satisfactores.

Ahora bien, no se trata sólo distinguir entre necesidades y satisfactores, sino de 
sumar a estas dos la noción de bienes materiales ("económicos", dice Max-Neef). Como se ha señalado, las modalidades de satisfacción varían según las épocas y de acuerdo a las culturas, condiciones económicas o los recursos de los que se dispone. Según el chileno, si los satisfactores son "lo histórico de las necesidades", lo "culturalmente determinado", los bienes materiales o económicos son "su materialización" (1998: 53). Lo cual se traduce, por ejemplo, en que los bienes, como él mismo apunta, potencian los satisfactores "para vivir las necesidades de manera coherente, sana y plena". Hablamos de los "objetos y artefactos que permiten afectar la eficiencia de un satisfactor, alterando así el umbral de actualización de una necesidad, ya sea en sentido positivo o negativo" (1998: 56). Se advierte que tales bienes no pueden ocupar, en relación a las necesidades y los satisfactores, una posición menor: "Mientras un satisfactor es en sentido último el modo por el cual se expresa una necesidad, los bienes son en sentido estricto el medio por el cual el sujeto potencia los satisfactores para vivir sus necesidades" (1998: 51).

No cabe duda, por lo demás, de que al introducirlos obtenemos una perspectiva mucho más rica y compleja del diseño: se trata de pensar los lenguajes de patrones como instancias asociadas a nuestros hábitos y necesidades, pero añadiendo a esa relación los bienes que movilizan, los recursos que se consumen para ello, los impactos que producen; en términos generales, cómo afectan a las condiciones medioambientales o ecológico-energéticas que hacen posible la vida de la especie humana. "El que un satisfactor pueda tener efectos distintos en diversos contextos depende no sólo del propio contexto, sino también en buena parte de los bienes que el medio genera, de cómo los genera y de cómo organiza el consumo de los mismos" (1998: 51). La reflexión sobre nuestros sistemas habitacionales debe poner en el centro el modo en que se concreta u objetiva esa "causación recíproca" entre bienes y satisfactores que es característica de toda cultura y de sus modelos de crecimiento o desarrollo. No tener esto en cuenta es adoptar un enfoque limitado, ciego ante las fracturas metabólicas sobre las que se organizan nuestras sociedades, y peligroso. Diremos, así, que una hipotética teoría de la vida bien posicionada o de la "integridad habitacional" exige una reflexión rigurosa sobre los bienes que hacen posible una vida buena. Ahora bien, desde un punto de vista necesariamente universalizable. Nos corresponde pensar a fondo, advierte Sloterdijk, "la conexión de inmunidad y comunidad" (2006: 409). El sujeto político aquí no viene determinado por el Estado o la nación, sino por la pertenencia a la especie humana. Es seguramente el sujeto político propio de la época del Antropoceno: la humanidad en su conjunto, constituida por la amenaza de sus condiciones mismas de habitabilidad.

\subsection{Tipos de satisfactores y límites planetarios}

La pregunta que sigue es cuándo y bajo qué circunstancias el conjunto de habitabilidades característico de nuestra cultura incluye o no buenas modalidades de satisfacción. Para responder a ello, Max-Neef propone una tipología de al menos cinco satisfactores (cinco tipos de patrones habitacionales, diremos), quellama "destructores", "inhibidores", "singulares", "pseudo-satisfactores" y "satisfactores sinérgicos". Los primeros, explica el chileno, "no sólo aniquilan la posibilidad de su satisfacción en un plazo medio [al ser aplicados], sino que imposibilitan, por sus efectos colaterales, la satisfacción adecuada de otras necesidades"; los segundos son "aquellos que por el modo en que satisfacen (generalmente sobresatisfacen) una necesidad determinada, dificultan seriamente la posibilidad de satisfacer otras necesidades"; mientras que los terceros y los cuartos son, respectivamente, satisfactores "que apuntan a la satisfacción 
de una sola necesidad, siendo neutros respecto a la satisfacción de otras necesidades" y que "estimulan una falsa sensación de satisfacción de una necesidad determinada". Por último, los satisfactores sinérgicos son "aquellos que por la forma en que satisfacen una necesidad determinada, estimulan y contribuyen a la satisfacción simultánea de otras necesidades. Su principal atributo es el de ser contrahegemónicos en el sentido de que revierten racionalidades dominantes tales como las de competencia y coacción" (1998: 64-65).

Una vez presentado el cuadro, Max-Neef propone clasificar los cuatro primeros como satisfactores de carácter exógeno, y los sinérgicos como endógenos; lo que significa que los exógenos son "tradicionalmente impulsados de arriba hacia abajo... impuestos, inducidos, ritualizados o institucionalizados"; mientras que los endógenos expresan "procesos liberadores... de personas libres, capaces, potencialmente o de hecho, de diseñar sus proyectos de vida en común" (1998: 65). Sin embargo, dado que él mismo reconoce que los satisfactores sinérgicos también pueden ser impulsados por el Estado, la diferencia importante, a nuestro parecer, tiene que ver más bien con la calidad de la agencia que exigen estos últimos; esto es: con el tipo de control que se ejerce sobre las modalidades de satisfacción de las necesidades, así como sobre la producción, distribución y naturaleza de los bienes materiales de los que depende su satisfacción. De lo que se trata es de encontrar un punto de vista que unifique correctamente el diseño de habitabilidades bajo los principios de una concepción crítica de la razón práctica; y ésta no habría de explicarse ya, según Broncano, en términos de simples imperativos, sino más bien a través de "un examen cuidadoso de las condiciones bajo las cuales la agencia humana se convierte en una agencia razonablemente virtuosa, de los condicionantes de la calidad de la agencia" (2005). Esta perspectiva matiza la idea de Max-Neef y permite profundizar en la dimensión democrática del diseño, que conecta perfectamente con la defensa de la colaboración y la participación ciudadana (de calidad, por tanto) ya comentadas.

Ahora bien, si observamos los conflictos como desajustes en la satisfacción de necesidades, en la medida en que su correcta satisfacción denota un desarrollo pleno, saludable y bueno de las mismas, entonces cabe suponer que será importante no pasar por alto tampoco que la calidad de la satisfacción de las necesidades dependerá no sólo del control democrático que ejerzamos sobre dicha satisfacción, sino también de que se respete la pluralidad axiológica que nos constituye como seres humanos; es decir, De que los lenguajes de patrones organicen y conecten, de manera ecológicamente viable, secuencias o cursos-de-acción para las muchas necesidades que tenemos. Por ende, convendremos en que la satisfacción de necesidades no puede ser valiosa ni aceptable si no se hace eco de que las necesidades, como apunta Max-Neef, "deben entenderse como un sistema en el que se interrelacionan e interactúan” (1998: 41).

Sin embargo, esta reflexión sobre necesidades, satisfactores y bienes, se quedaría a medias si no se amplía con un marco apropiado en el que se ordene correctamente el problema de la crisis ecológica global. Aunque, según hemos advertido, no es una cuestión que pretendamos desarrollar aquí, se trata de una parte fundamental de la filosofía de la habitabilidad y, por ende, del diseño de patrones. Entre otras cosas, nos conduce a plantear cuál es la escala -o mejor dicho: cuáles son las escalas- del problema de la habitabilidad. Recientemente, Campillo ha realizado sugerencias muy interesantes, intentando recuperar la tríada kosmos, pólis y éthos, con el objetivo de cuadrar un mapa adecuado a los desafíos globales, donde el yo y el nosotros se piense 
junto con la naturaleza (Campillo 2018). Lo mismo encontramos en Max-Neef al subrayar que necesidades, satisfactores y bienes deben articularse normativamente teniendo en cuenta tres dominios: "uno mismo (Eigenwelt)", el "grupo social (Mitwelt)" y "la relación con el medio ambiente (Umwelt)" (1998: 43). De acuerdo con estas posiciones, y como consecuencia también de introducir la dimensión constitutiva en la definición de los patrones, reconocemos que una de las escalas de lo habitacional es el planeta, cuyos límites deben ser un factor de primer orden (por ejemplo, a la hora de dar contenido al principio de limitación) en los procesos de diseño y planificación urbana. Por supuesto, habría que contar aquí con la noción de "límites planetarios" de Rockström y su equipo (2009) como análisis de base, pero no seguiremos ahora esta pista. Interesa, más bien, un paso previo, que tiene que ver con el marco general dentro del cual ordenar e integrar lo dicho hasta aquí: la naturaleza o el planeta como escala constitutiva de lo habitacional, los diferentes tipos de bienes materiales y las dos clases de necesidades (existenciales y axiológicas). En este sentido, proponemos hablar de cuatro dominios habitacionales básicos; dominios que los patrones de habitabilidad declinan siempre bajo una articulación determinada (y están, al mismo tiempo, interpenetrados por ellos).

\section{Algunas correcciones a partir de un enfoque basado en procesos}

En base al modelo de patrones que se ha presentado, y con el objetivo de profundizar en nuestro marco de trabajo, se puede hablar de cuatro dominios habitacionales básicos: [1] de acuerdo con lo dicho sobre la naturaleza o el medioambiente como factor determinante de la habitabilidad, el de los elementos que constituyen el entorno biofisico, natural, donde se despliegan nuestros estilos habitacionales; [2] tal y como reclama Max-Neef al hablar de bienes materiales, el de los bienes e infraestructuras, es decir, las cosas o objetos que diseñamos o cultivamos para adaptarnos al mundo, darle una forma técnicamente orientada y, por tanto, organizar nuestra experiencia como especie ([1] y [2] responderían a la diferencia entre "capital natural" y "capital cultivado" de Arias Maldonado (2018)); [3] el de las acciones que realizamos, lo que vendría a ser el dominio de la praxis propiamente dicha, que se objetiva siempre movilizando o usando elementos, bienes e infraestructuras (este tercer dominio nos permitirá observar las "necesidades existenciales" desde un punto de vista renovado, más estrechamente vinculado a la cuestión de la habitabilidad); y [4] el de los sistemas de racionalidad en función de los cuales se ordenan, valoran, y articulan los anteriores tres dominios bajo programas y principios de uno u otro tipo, y cuya introducción, además, se presenta como absolutamente necesaria desde el momento en que decidimos introducir la cuestión axiológica al analizar la estructura misma de los patrones habitacionales.

Ahora bien, ¿cómo pensamos estos dominios o ámbitos? Nuestra propuesta es hacerlo en términos procesuales, siguiendo algunas ideas expuestas por Nicholas Reschel (2000). Sin embargo, una primera pregunta se impone: ¿qué es un proceso? Según Nicholas Rescher un proceso es: (1) un complejo o conjunto de acontecimientos (complex of occurrences) cuya unidad se despliega en diferentes fases o estadios; además, (2) se trata de un conjunto unitario de acontecimientos que posee una cierta "coherencia e integridad temporal"; y además, añade Reschel, un proceso (3) tiene una estructura, un patrón de organización o un modo general según el cual tales acontecimientos se organizan (a formal generic patterning of occurrence). Según esta idea de procesos, entre las conclusiones destacables se encuentra el hecho de su naturaleza radicalmente histórica: 
los procesos existen solamente a través de sus "concretas manifestaciones históricas" (2000: 25); por tanto, se entienden los procesos como espacial y temporalmente determinados. No obstante, para Rescher el núcleo del asunto tiene que ver con su "identidad estructural", lo que permite, en última instancia, hablar de acontecimientos secuencialmente ordenados según patrones característicos. En suma: una unidad de acontecimientos cuyo despliegue se realiza por fases, coherencia temporal que implica la conservación de esa unidad a través de su despliegue, y una estructura característica de esa unidad, que viene a ser la expresión mínima de su identidad.

A partir de aquí, Reschel establece una posible clasificación de los modos procesuales o los tipos de procesos teniendo en cuenta tres criterios: (1) el carácter de la estructura [structure type], (2) la naturaleza o contenido de los acontecimientos [occurrence type], y (3) el resultado final de los procesos [result type]. De acuerdo con la "estructura secuencial" de los procesos, los que según Reschel responden a la pregunta "what sort of structure?", se distinguen cuatro tipos de procesos: (a) procesos causales (la floración); (b) procesos operatorios basados en reglas (realizar una división); (c) procesos ceremoniales (lavarse las manos antes de comer); y (d) procesos performativos (tocar una pieza al piano). De acuerdo con el segundo bloque de procesos, que se recogen bajo la pregunta "what sort of occurrences?", existirían un total de cuatro: (e) políticos, (f) matemáticos, (g) mentales y (h) biológicos. Por último, tendríamos los (i) procesos de estilización social, (j) de resolución de problemas y (k) de producción de productos, en respuesta a la pregunta "what sort of result?", conformando el tercer bloque de clases de procesos.

Sin embargo, tenemos serias dudas de que este esta clasificación sea útil si lo que interesa es conformar un marco explicativo y crítico del fenómeno de la habitabilidad. Además, Reschel no explica las relaciones que existen -o si más bien no existen- entre los once procesos que identifica. Por tanto, desde nuestro punto de vista, se podrían hacer algunas correcciones que presentamos a continuación:

1. De acuerdo con el criterio de la estructura, que consideramos fundamental, nuestra posición, tal y como indicábamos al principio, resulta más pertinente distinguir entre estructuras procesuales de orden natural (los procesos característicos de un ecosistema), estructuras procesuales de orden técnico (el cultivo de alimentos, el diseño de un barrio, la decoración de una casa, etc.), estructuras procesuales de orden pragmático (descansar, ir a trabajar, cocinar, etc.) y estructuras procesuales de orden sistémico-racional (la ciencia, la economía, el derecho, la religión, etc.). Los lenguajes de patrones, las formas según las cuales respondemos al problema de la habitabilidad, se encontrarían siempre en el cruce de estos cuatro procesos (origen, los cuatro, de su profunda fragilidad).

2. Si respetáramos la clasificación de Reschel, tendríamos que explicar a continuación qué procesos de contenido es necesario considerar a partir de las diferentes estructuras procesuales señaladas. Pensemos por ejemplo en las acciones. Evidentemente, una teoría de la habitabilidad basada en los lenguajes de patrones debe dar cuenta de nuestros patrones de acción, esto es, de los procesos que ponemos en marcha a través de lo que hacemos. Parece razonable afirmar que no todas nuestras acciones son iguales: dormir, respirar, cocinar, pasear, escribir, etc. Pero, ¿cómo distinguirlas? Ha habido intentos interesantes, como el de Arendt (2009), que diferencia 
entre labor, trabajo y acción. Nosotros, en cambio, sugerimos hablar de cuatro grandes bloques de patrones de acción o procesos pragmáticos, una taxonomía cualitativa bajo la cual quizá podríamos comprender todo el repertorio de acciones humanas que son relevantes en términos habitacionales.

En primer lugar, los gestos o procesos pragmáticos que denominamos de concentración; por otro lado, los que entendemos como gestos de dispersión; en tercer lugar, los que hemos dado en llamar de conservación; y por último, los gestos o procesos pragmáticos de generación. Los primeros tienen que ver con nuestra tendencia a hacer cosas en un mismo lugar (dormir, estudiar, rezar, cuidar el huerto); los segundos más bien con la movilidad o el acto de desplazarse (ir a trabajar o a la biblioteca, pasear, transportar mercancía, etc.); los terceros tienen que ver con nuestros consumos o actos automáticos (respirar, comer, etc.); y los cuartos más bien con nuestras capacidades de generar, tunear o crear cosas distintas (un poema, una silla, un algoritmo, una teoría, etc.). Los cuatro son procesos que dan contenido, una concreción precisa, a las estructuras procesuales de orden pragmático; y los cuatro son procesos, por tanto, mediante cuya articulación, en base a conjuntos de satisfactores o patrones, según decimos, damos satisfacción a nuestras necesidades.

Para un programa de investigación del diseño centrado en lo habitacional, es importante proporcionar un cuadro riguroso de lo que al principio de este artículo hemos llamado "patrones de acción". Estos funcionan como los "sobreentendidos" de los patrones de habitabilidad, pero ocupan un lugar confuso o menor en la teoría de las necesidades de Max-Neef, y Alexander tampoco reflexiona sobre ellos convenientemente. Pues bien, gracias al enfoque basado en procesos, podemos fijar los procesos de orden pragmático como una estructura fundamental de lo habitacional, y utilizar los cuatro tipos de gestos citados -de concentración, de dispersión, de conservación y de generación-para sustituir las "necesidades existenciales" del chileno. De este modo, tendríamos cuatro necesidades pragmático-estructurales, que describen el repertorio de acciones de las que el diseño debe dar cuenta. Consideramos que una teoría crítica de nuestros sistemas habitacionales, una filosofía de la habitabilidad, no puede pasar por alto las formas en que hacemos efectivos los distintos procesos de orden pragmático que hemos descrito.

\section{Resumen final}

En este artículo, que compartimos como primer esbozo de una filosofía de la habitabilidad, se ha presentado un modelo de interpretación de los patrones, entendidos como instrumentos de racionalidad de lo habitacional, describiendo además los factores que determinan los procesos de diseño. Se ha propuesto pensar el diseño de patrones dentro de una teoría de las necesidades y la noción de "integridad habitacional". Se ha apuntado también que esta integridad debe articularse con otros equilibrios a escala planetaria. Y por último se ha propuesto profundizar en esta reflexión aplicando un enfoque basado en procesos, con el objetivo de crear un mapa teórico -del que aquí presentamos una pequeña parte- del problema de la habitabilidad. Éste debería ayudar o conducir una reflexión colectiva, y rigurosa, sobre nuestro futuro, el de nuestras ciudades, y los patrones habitacionales que debemos diseñar ante la multiplicación de los riesgos y la puesta al descubierto de nuestra vulnerabilidad. 


\section{Bibliografía}

Alexander, C. 1969. Ensayo sobre la sintesis de la forma. Buenos Aires: Infinito.

— 1971. La estructura del medio ambiente, Barcelona: Tusquets. , 1981. El modo intemporal de construir, Barcelona: GG. 1980. Un lenguaje de patrones, Barcelona: GG.

Alexander, C. et alt.. 1976. Urbanismo y participación. El caso de la Universidad de Oregón, Barcelona: GG.

Arendt, H. 2009. La condición humana, Barcelona: Paidós.

Baudrillard, J. 1974. Crítica de la economía politica del signo, México: Siglo XXI.

Berger, P., Luckmann, T. 2001. La construcción social de la realidad, Buenos Aires: Amorrortu.

Bourdieu, P. 2007. El sentido práctico, Buenos Aires: Siglo XXI.

Broncano, F. 2000. Mundos artificiales, Barcelona: Paidós. , 2009. La melancolía del ciborg, Barcelona: Herder. 2005. "La agencia técnica", en Revista CTS, n 5, vol. 2.

Campillo, A. 2018. Mundo, nosotros, yo. Ensayos cosmopoliéticos, Barcelona: Herder Echeverría, J. 2003. La revolución tecnocientifica. Madrid: FCE. , 2017. El arte de innovar. Madrid: Plaza y Valdés.

Goffman, E. 2006. Frame Analysis. Los marcos de la experiencia, Madrid: Siglo XXI.

Lahire, B. 2004. El hombre plural, Barcelona: Bellaterra.

Lawler, D., Vega Encabo, J. 2011. "Realizabilidad múltiple y clases de artefactos", Revista CTS, n ${ }^{\circ} 19$, vol. 7.

Lefébvre, H. 1976. Espacio y politica, Barcelona: Península.

Loos, A. 2003. Dicho en el vacío. 1897-1900, Murcia: Arquilectura

Luhmann, N. 1998. Sistemas sociales, México-Barcelona, Iberoamericana: Anthropos. Lukács, G. 2007. Marx, ontología del ser social. Madrid: Akal.

Maldonado, M. A. 2018. Antropoceno. La política en la era humana. Barcelona: Taurus. Mauss, M. 1979. Sociología y antropología. Madrid: Tecnos.

Max-Neef, M. 1998. Desarrollo en escala humana. Montevideo-Barcelona: Norda-Icaria Reschel, N. 2000. Process Philosohy, University of Pittsburgh Press.

Riechmann, J. 2014. Un buen encaje en los ecosistemas. Madrid: Catarata.

Rockström, J., Steffen, W., Noone, K., et al., "A safe operating space for humanity", en Nature, vol. 461, 2009.

Sánchez Criado, T. 2008. Tecnogénesis. La construcción técnica de las ecologías humanas, Madrid: AIBR.

Sempere, J. 2018. Las cenizas de Prometeo. Barcelona: Pasado y Presente.

Sloterdijk, P. 2006. Esferas, Madrid: Siruela.

Vega Encabo, J. 2004. “'Traslación' y adaptación de técnicas. Tecnologías apropiadas y procesos de transferencia", Revista CTS, n ${ }^{\circ} 3$, vol. 1 . 


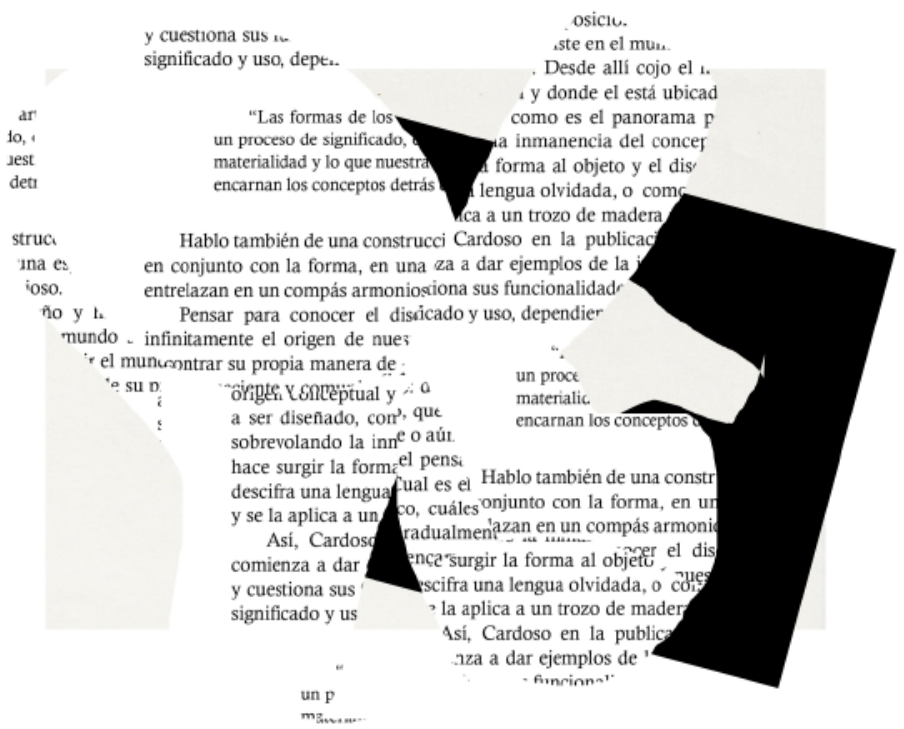

"Lo impreso exige una humildad de espíritu por cuya falta muchas de las bellas artes se tambalean ahora en experimentos de autoconciencia y sensiblería. No hay nada simple ni aburrido en lograr una página transparente. La ostentación vulgar es el doble de fácil que la disciplina".

Beatrice Warde, The Crystal Goblet, or why printings should be invisible (1930)

"El diseño que es objetivo, comprometido con el bien común, bien compuesto y delicado, constituye la base del comportamiento democrático".

Josef Müller-Brockmann, Grid and Design Philosophy (1981) 

EDITA

\section{SEyTA.}

SOCIEDAD ESPAÑLAA
DE ESTETICA Y TEORIA DE LAS ARTES

CON LA COLABORACIÓN DE

\begin{tabular}{|c|c|c|}
\hline 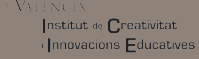 & $\begin{array}{l}\text { VNIVIRSIIA } \\
\text { In VVIIINCI Departament de Filosofia }\end{array}$ & 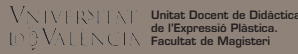 \\
\hline $\begin{array}{l}\text { TitTicA } \\
\text { SoFFA }\end{array}$ & 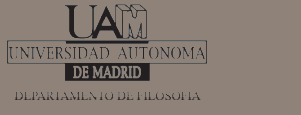 & $\begin{array}{l}\text { UAB } \\
\text { Universitat Autònoma } \\
\text { de Barcelona }\end{array}$ \\
\hline
\end{tabular}

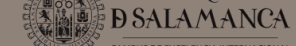

https://ojs.uv.es/index.php/LAOCOONTE/index 